\title{
Hepatitis B Virus Infection in Children and Adolescents in a Hyperendemic Area: 15 Years after Mass Hepatitis B Vaccination
}

Yen-Hsuan Ni, MD, PhD; Mei-Hwei Chang, MD; Li-Min Huang, MD, PhD; Huey-Ling Chen, MD; Hong-Yuan Hsu, MD, PhD; Tai-Yuan Chiu, MD; Keh-Sung Tsai, MD, PhD; and Ding-Shinn Chen, MD

Background: Hepatitis B virus (HBV) infection is hyperendemic in Taiwan. Before universal HBV immunization was started in Taiwan in 1984, the carrier rate for hepatitis B surface antigen (HBsAg) was $15 \%$ to $20 \%$ in the general population.

Objective: To quantify the population impact of a mass vaccination program for HBV 15 years after its implementation.

Design: Descriptive analysis of serologic markers of HBV in healthy children and adolescents.

Setting: Chung-Cheng District, Taipei City, Taiwan, in 1999.

Participants: 1357 persons younger than 15 years of age, who were born after the implementation of universal HBV vaccination, and 559 persons 15 to 20 years of age, who were born before the program began.

Measurements: Repeated serologic surveys similar to those done before and 5 and 10 years after the national vaccination program was implemented. All participants were tested for serum HBsAg, its antibody (anti-HBs), and hepatitis B core antibody (anti-HBc).
Results: During the 15 years since the vaccination program was implemented, the prevalence of $\mathrm{HBsAg}$ among persons younger than 15 years of age decreased from $9.8 \%$ in 1984 to $0.7 \%$ in 1999; among persons 15 to 20 years of age, the 1999 prevalence of HBsAg was $7 \%(P<0.001)$. Hepatitis B core antibody seropositivity, which represents HBV infection, was found in $2.9 \%$ of persons younger than 15 years of age and in $20.6 \%$ of persons 15 to 20 years of age $(P<0.001)$; in the same age groups, the rate of anti-HBs seropositivity was $75.8 \%$ and $70.7 \%$, respectively $(P=0.02)$.

Conclusions: Universal vaccination significantly decreased the HBV carrier rate and infection rate among children and adolescents born since the program began. By decreasing the carrier pool, continuation of the national HBV immunization program should prevent HBV infection in the children of Taiwan, and, subsequently, adults as well.

Ann Intern Med. 2001;135:796-800.

www.annals.org For author affiliations, current addresses, and contributions, see end of text. See related article on pp 759-768 and editorial comment on pp 835-836.
$\mathrm{H}$ epatitis B virus (HBV) infection is an important cause of chronic hepatitis, cirrhosis, and hepatocellular carcinoma in many parts of the world, including Taiwan $(1,2)$. Up to $15 \%$ to $20 \%$ of the general population in Taiwan are chronic carriers of hepatitis B surface antigen ( $\mathrm{HBsAg})(3,4)$. Most chronic carriage of HBV results from infection in early childhood, especially before 2 years of age (5-7). Taiwan launched the world's first nationwide universal vaccination program in 1984 to prevent infection in the early years of life (8). In addition to decreasing the proportion of carriers and the prevalence of $\mathrm{HBV}$ infection in the current young generation (9), the universal vaccination program has also resulted in a decreased incidence of childhood hepatocellular carcinoma (10).

To study the effect of this universal vaccination program, we conducted a series of prospective seroepidemiologic surveys in Chung-Cheng District, Taipei City, Taiwan. The first survey was conducted shortly before the mass vaccination program began in 1984 (6), fol- lowed by similar surveys in 1989 (11) and 1994 (12). We report findings that extend our follow-up observations to 1999 - 15 years after the start of the program.

\section{Methods}

National Vaccination Program

The national program of universal $\mathrm{HBV}$ vaccination in Taiwan began on 1 July 1984 (8). At that time, only the newborn infants of mothers who were HBsAg carriers were vaccinated. The vaccination program was extended in June 1987 to include all newborn infants and in July 1987 to cover all children of preschool age. The program was further extended to school children, teenagers, and then adults from 1988 to 1990 . Since 1991, the vaccination records of first-grade children have been checked, and children without a complete set of previous vaccinations have been given "catch-up" HBV vaccinations. Before July 1992, four doses of plasmaderived vaccine were administered in children before 1 


\section{Hepatitis B Virus Infection after 15-Year Mass Vaccination 1 BRIEF COMMUNICATION}

week of age and again at 1, 2, and 12 months of age; after July 1992, three doses of recombinant (yeastderived) vaccine were administered before 1 week and at 1 month and 6 months of age. Since 1984, newborns whose mothers test positive for hepatitis $\mathrm{B}$ e antigen ( $\mathrm{HBeAg})$ have also received hepatitis B immunoglobulin, $0.5 \mathrm{~mL}$ (100 IU), within 24 hours after birth. The vaccination program has been described in greater detail elsewhere $(8,12)$.

We defined the vaccination coverage rate as the percentage of children receiving at least three doses of $\mathrm{HBV}$ vaccine. We assessed the vaccination histories of the studied population by examining their vaccination cards and by taking a history from their parents. We classified the vaccination status as unknown for persons with a missing vaccination card or a vague vaccination history.

\section{Participants}

From March 1999 to October 1999, serum samples were collected from 1916 children and adolescents from two groups: 1) 1357 apparently healthy persons younger than 15 years of age $(721$ male participants and 636 female participants), who were born after the launch of the universal vaccination program, and 2) 559 persons (297 male participants and 262 female participants) 15 to 20 years of age, who were born before universal vaccination. We recruited participants for the baseline and follow-up seroepidemiologic studies in Chung-Cheng District, Taipei City. In 1999, Chung-Cheng had a population of 165388 citizens; 35005 of the citizens were younger than 15 years of age, and 47565 were younger than 20 years of age. From 1994 to 1999, the population was stable, with an average annual migration rate of less than $4.8 \%$. The annual family income, $\$ 39963$ (in U.S. dollars), was the third highest among the 12 districts in Taipei (13). From 1985 through 1990 , the HBsAg carrier rate among pregnant women$14 \%$ (14) — was similar to the national average $(3,4)$.

The 1916 participants in our 1999 study consisted of 1) 157 children younger than 3 years of age enrolled from the Well-Baby Clinic of the National Taiwan University Hospital Department of Pediatrics and from two day care centers; 2) 232 children 3 to 6 years of age recruited from two kindergarten classes; 3) 763 children 7 to 12 years of age enrolled from one public elementary school; 4) 205 children and adolescents 12 to 15 years of age enrolled from one public junior high school; 5) 219 adolescents 15 to 18 years of age enrolled from one high school; and 6) 340 first-year undergraduate students at the National Taiwan University, 19 to 20 years of age.

We recruited the child and adolescent participants through poster advertisements and by invitation from the health staff of the Department of Pediatrics, National Taiwan University Hospital. The university student participants and the parents of enrolled children gave written, informed consent and provided the vaccination history of the participant, according to his or her personal health booklet. (The booklet, which is used to record a person's vaccination history, is provided to the parents of all newborns by the Health Bureau of City Hall.)

\section{Serologic and Statistical Analyses}

We analyzed serum samples for $\mathrm{HBsAg}, \mathrm{HBsAg}$ antibody (anti-HBs), and hepatitis B core antibody (anti$\mathrm{HBc}$ ) by using enzyme immunoassay (Abbott Laboratories, North Chicago, Illinois). We examined betweengroup differences in frequency by using the chi-square test with Yates correction or the Fisher exact test, where appropriate. A $P$ value less than 0.05 was considered significant. Data analyses were performed by using GraphPad Prism, version 3.00 (GraphPad Software, Inc., San Diego, California).

\section{Role of the Funding Source}

The funding source had no role in the collection, analysis, and interpretation of the data or in the decision to submit the paper for publication.

\section{RESULTS}

In 1999, the vaccination coverage rate was greater than $90 \%$ among children younger than 8 years of age and $80 \%$ to $86 \%$ among children 8 to 15 years of age (Table). These figures might be underestimates because some of the participants, particularly in the older age group, had missing vaccination cards; in other cases (for 23 of the 541 children younger than 8 years of age and 63 of the 766 participants 8 to 15 years of age), the parents could not recall the vaccination history. Infants had a lower coverage rate than other age groups because some of them had not yet finished their vaccination schedule (Appendix Table).

6 November 2001 Annals of Internal Medicine $\mid$ Volume 135 • Number 9|797 


\section{BRIEF Communication Hepatitis B Virus Infection after 15-Year Mass Vaccination}

Table. Seroprevalence of Hepatitis B Surface Antigen and Its Antibody in Chung-Cheng District, Taipei City, Taiwan, in $1984,1989,1994$, and 1999*

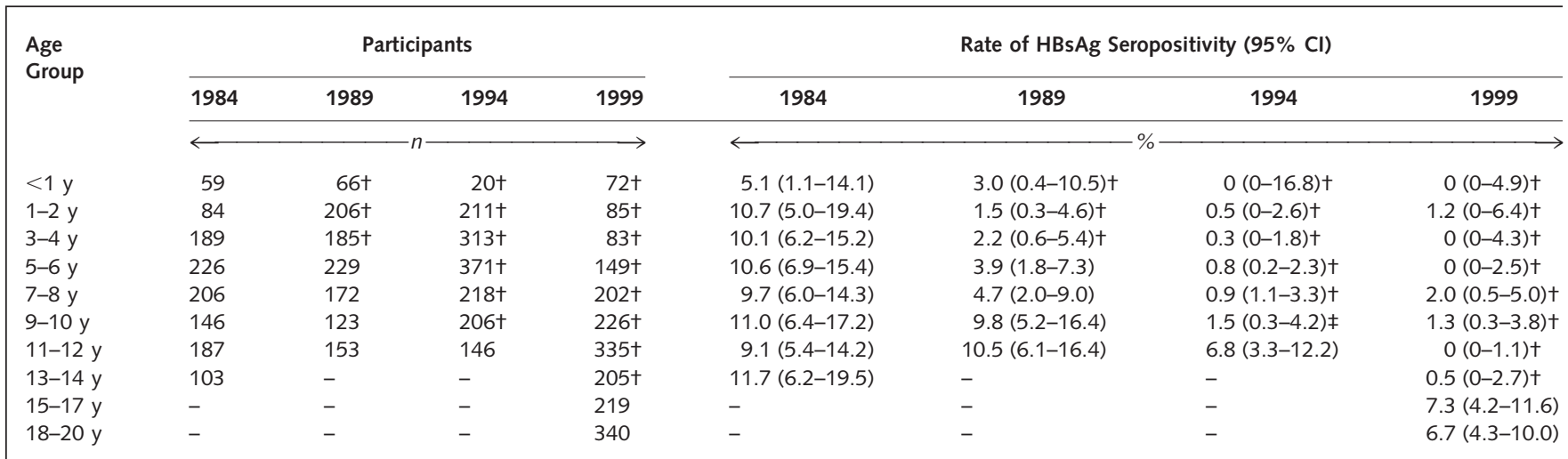

* The first survey was conducted shortly before the mass vaccination program began in 1984 (6). Similar follow-up surveys were conducted in 1989 (11), 1994 (12), and 1999 (the current study). Anti-HBs = hepatitis B surface antigen antibody; $\mathrm{HBsAg}=$ hepatitis B surface antigen.

† Persons born after implementation of the universal hepatitis B virus vaccination program in Taiwan in 1984.

₹ Some participants were born before and others after implementation of the national vaccination program.

The prevalence of HBsAg in children younger than 15 years of age, $0.7 \%$ (9 of 1357), was considerably lower than the rate of $7 \%$ (39 of 559) observed in par-

Figure. Longitudinal perspective of the proportion of hepatitis $B$ surface antigen carriers among the cohorts of 0 to 1 year of age in 1984 (circles) and 1989 (squares) in Chung-Cheng District, Taipei City, Taiwan.

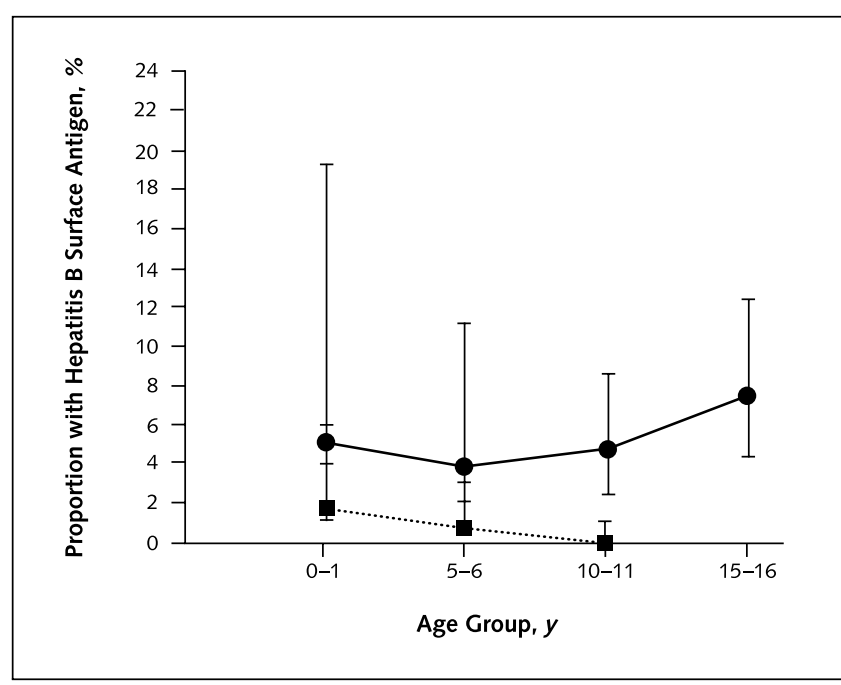

Children in the 19840 - to 1-year age cohort, who were born before universal vaccination in Taiwan, had a carrier rate of $5.1 \%$ in 1984 , $3.9 \%$ in 1989 (at age 5 to 6 years), $4.7 \%$ in 1994 (at age 10 to 11 years), and $7.5 \%$ in 1999 (at age 15 to 16 years). These proportions are significantly higher than those observed over time in the 19890 - to 1-year age cohort, who were born since the national vaccination program started, at the corresponding age points (from the survey years 1989, 1994, and 1999 , respectively). ticipants older than 15 years of age, who were born before the universal vaccination program $(P<0.001)$. Of the 9 children who were born after the vaccination program was instituted and tested positive for $\mathrm{HBs} A g$, only 1 had not received the scheduled vaccinations, and the mother of this child was also $\mathrm{HBsAg}$ positive. According to their vaccination cards, the 8 other participants had received at least three doses of the HBV vaccine, and the first dose had been given within 1 week of birth. Seven of these 8 participants had mothers who were $\mathrm{HBsAg}$ carriers, and the remaining participant was living with two grandparents who were $\mathrm{HBsAg}$ positive. All 9 participants tested positive for anti-HBc. Eight of these $9 \mathrm{HBsAg}$ carriers had received the plasma-derived vaccine, and 1 had received the yeast-derived recombinant vaccine; however, type of vaccine did not affect the rate of HBsAg seropositivity (8 of 968 persons who received the plasma-derived vaccine were carriers vs. 1 of 389 who received the yeast-derived vaccine; $P>0.2$, Fisher exact test).

The overall prevalence of anti-HBs in persons younger than 15 years of age in 1999 was $75.8 \%$. We observed the highest prevalence of anti-HBs in children younger than 5 years of age (Table). The longitudinal perspective of HBsAg carriers in cohorts 0 to 1 years of age is shown in the Figure.

The rate of anti-HBc seropositivity was $2.9 \%$ in persons younger than 15 years of age but was $20.6 \%$ in persons 15 years of age or older $(P<0.001)$. In con- 


\section{Table-Continued}

\begin{tabular}{|c|c|c|c|}
\hline \multicolumn{4}{|c|}{ Rate of Anti-HBs Seropositivity $(95 \% \mathrm{Cl})$} \\
\hline 1984 & 1989 & 1994 & 1999 \\
\hline \multicolumn{4}{|c|}{$\longleftarrow$ $\% \longrightarrow$} \\
\hline $39.0(26.5-52.5)$ & $83.3(72.2-91.2) \dagger$ & $90.0(68.3-98.8) \dagger$ & $79.2(68.0-87.9)+$ \\
\hline 10.7 (5.0-19.4) & $85.0(79.3-89.6)+$ & $88.2(83.0-92.2) \dagger$ & $91.8(83.8-96.6)+$ \\
\hline $14.3(9.7-20.1)$ & $22.7(16.9-29.4) \dagger$ & $81.2(76.4-85.3) \dagger$ & $88.0(79.0-94.1)+$ \\
\hline $16.8(12.2-22.3)$ & $20.1(15.1-25.8)$ & $77.4(72.8-81.5) \dagger$ & $79.9(72.5-86.0)+$ \\
\hline $22.8(17.2-29.1)$ & $20.9(15.1-27.7)$ & $76.2(69.9-81.7) \dagger$ & $71.8(65.0-77.8)+$ \\
\hline $24.7(17.9-32.4)$ & $24.4(17.1-32.9)$ & $75.2(68.7-81.0) \dagger$ & $68.6(62.1-74.8)+$ \\
\hline $36.9(30.0-44.3)$ & $19.0(13.1-26.1)$ & $71.9(63.9-79.0)$ & $70.4(64.7-74.7)+$ \\
\hline $41.8(32.1-51.9)$ & - & - & $80.0(73.9-85.2)+$ \\
\hline- & - & - & $84.9(79.5-89.4)$ \\
\hline - & - & - & $61.5(56.1-66.6)$ \\
\hline
\end{tabular}

trast, the rate of anti-HBc seropositivity among children younger than 15 years of age was $26.2 \%$ in 1984 (6), $14.5 \%$ in 1989 (11), and 4.0\% in 1994 (12).

\section{Discussion}

The prevalence of HBsAg among children younger than 15 years of age decreased from $9.8 \%$ to $0.7 \%$ in the 15 years since implementation of the universal vaccination program. A high coverage rate for $\mathrm{HBV}$ vaccination is crucial for decreasing the prevalence of HBV infection. We observed a vaccination rate of at least $80 \%$ among children younger than 15 years of age and as high as $97 \%$ among children 4 years of age or younger. A nationwide series of seroepidemiologic studies of three cohorts of children 6 years of age in 1989,
1991 , and 1993 reported that the vaccination rates for HBV ( $\geq 3$ doses of vaccine) were $27.8 \%, 60.7 \%$, and $88.7 \%$, respectively (9). The age of these three cohorts in 1999 correspond to the age groups of 15 to 18 years, 13 to 14 years, and 11 to 12 years in our study. The data from these three national cohort studies confirm that the vaccination rate in our sample is similar to the vaccination rate for the corresponding age groups nationally.

Persons younger than 15 years of age in 1999 had a decreased rate of anti-HBc, a marker of HBV infection, compared with the rates in the corresponding age cohorts in our previous surveys. All persons with anti-HBc seropositivity have had HBV infection, but only some are carriers while others experience complete recovery. Therefore, the discrepancy between the prevalence of anti-HBc and HBsAg is explained by persons who were infected with HBV but did not become chronic carriers. It is likely the vaccination program, in addition to herd immunity, prevents these people from becoming carriers.

Vaccination failed to protect 8 children in our study from becoming HBsAg carriers. Among these children, the high proportion with a positive family history of $\mathrm{HBV}$ infection, and in particular the number with an $\mathrm{HBsAg-carrier}$ mother, is striking. Because all 8 children received their first vaccine dose within the first week of life, delayed vaccination cannot explain these vaccine failures. Possible explanations include presence of intrauterine $\mathrm{HBV}$ infection (15), inadequate vaccine response, or vaccine escape variants $(16,17)$.

From 1 to 12 years of age, the rate of anti-HBs seropositivity gradually decreased despite a steady vaccination coverage rate of greater than $85 \%$. This is per-

Appendix Table. Hepatitis B Vaccination History in Taiwanese Children, 1999*

\begin{tabular}{|c|c|c|c|c|c|c|c|}
\hline \multirow[t]{3}{*}{ Age Group } & \multirow[t]{2}{*}{ Participants } & \multicolumn{5}{|c|}{ Participants, according to Total Number of Lifetime Vaccinations for HBV } & \multirow{2}{*}{$\begin{array}{l}\text { Total Participants } \\
\text { Receiving } \geq 3 \\
\text { Vaccinations }\end{array}$} \\
\hline & & 0 & 1 & 2 & 3 & $\geq 4$ & \\
\hline & \multicolumn{6}{|c|}{$\longleftrightarrow-n \longrightarrow$} & $n(\%)$ \\
\hline$<1 \mathrm{y}$ & 72 & 0 & 17 & 35 & 19 & 1 & $20(28)$ \\
\hline $1-2 y$ & 85 & 0 & 1 & 0 & 83 & 1 & $84(98)$ \\
\hline $3-4 y$ & 83 & 3 & 0 & 0 & 74 & 6 & $80(96)$ \\
\hline $5-6 y$ & 149 & 6 & 4 & 5 & 103 & 30 & $133(89)$ \\
\hline $7-8$ y & 202 & 4 & 10 & 4 & 44 & 137 & $181(90)$ \\
\hline $9-10$ y & 226 & 10 & 12 & 8 & 57 & 133 & 190 (84) \\
\hline $11-12$ y & 335 & 8 & 12 & 13 & 50 & 239 & $289(86)$ \\
\hline $13-14$ y & 205 & 15 & 13 & 7 & 44 & 119 & $163(80)$ \\
\hline $15-17 y$ & 219 & 27 & 47 & 27 & 15 & 92 & 107 (49) \\
\hline
\end{tabular}

${ }^{*} \mathrm{HBV}=$ hepatitis $\mathrm{B}$ virus. 


\section{Brief CommunicATION Hepatitis B Virus Infection after 15-Year Mass Vaccination}

haps due to the waning of anti-HBs titers over time (18). Participant groups older than 15 years of age were still able to achieve a high rate of anti-HBs seropositivity; catch-up vaccinations in combination with natural booster in later life might explain this effect.

Our study demonstrates the tremendous effect of a mass vaccination program on the rate of $\mathrm{HBV}$ infection in children and adolescents in Taiwan. The universal vaccination program in Taiwan reduced the rate of chronic carriers and the total infection rate for HBV, as reflected by the decreased prevalence of $\mathrm{HBsAg}$ and anti-HBc. By the end of 2000, nearly 110 countries had implemented mass vaccination programs for $\mathrm{HBV}$. We anticipate that these efforts will lead to a greater worldwide control of $\mathrm{HBV}$ infection in the 21st century. Consequently, liver diseases caused by HBV infection should be better controlled (10). The remaining challenges will be to minimize the rate of vaccine failure and to deal with potential vaccine-related events, such as the emergence of escape surface mutants (17).

From National Taiwan University College of Medicine and National Taiwan University Hospital, Taipei, Taiwan.

Acknowledgments: The authors thank Dr. Ching-Fan Chung for assistance with statistical analysis. They also thank Ms. Su-Yau Kao, Ms. Alice Hsiu-Yu Lin, Ms. Jia-Bao Pang, and Ms. Jin-Le Shan for excellent technical assistance in data collection, case enrollment, and serologic assays.

Grant Support: By the Department of Health, Executive Yuan, Taiwan (grants DOH-89-DC-1017 and DOH-88-DC-1001).

Requests for Single Reprints: Mei-Hwei Chang, MD, Department of Pediatrics, National Taiwan University Hospital, 7 Chung-Shan South Road, Taipei 100, Taiwan; e-mail, mhchang@ha.mc.ntu.edu.tw.

Current Author Addresses: Drs. Ni, Chang, Huang, Chen, Hsu, Chiu, Tsai, and Chen: National Taiwan University Hospital, 7 Chung-Shan South Road, Taipei 100, Taiwan.

Author Contributions: Conception and design: Y.-H. Ni, M.-H. Chang.

Analysis and interpretation of the data: Y.-H. Ni, M.-H. Chang.

Drafting of the article: Y.-H. Ni, M.-H. Chang.

Critical revision of the article for important intellectual content: Y.-H. Ni, M.-H. Chang, L.-M. Huang, H.-L. Chen, H.-Y. Hsu, T.-Y. Chiu, D.-S. Chen.

Final approval of the article: Y.-H. Ni, M.-H. Chang, L.-M. Huang, H.-L. Chen, H.-Y. Hsu, T.-Y. Chiu, K.-S. Tsai, D.-S. Chen.

Provision of study materials or patients: Y.-H. Ni, M.-H. Chang, L.-M. Huang, T.-Y. Chiu, K.-S. Tsai, D.-S. Chen.

Obtaining of funding: Y.-H. Ni.

Collection and assembly of data: Y.-H. Ni, M.-H. Chang.

\section{References}

1. Beasley RP. Hepatitis B virus as the etiologic agent in hepatocellular carcinoma-epidemiologic considerations. Hepatology. 1982;2:21S-6S.

2. Beasley RP, Hwang LY, Lin CC, Chien CS. Hepatocellular carcinoma and hepatitis B virus. A prospective study of 22707 men in Taiwan. Lancet. 1981;2: 1129-33. [PMID: 6118576]

3. Sung JL, Chen DS, Lai MY, Yu JY, Wang TH, Wang CY, et al. Epidemiological study of hepatitis B virus infection in Taiwan. Chinese Journal of Gastroenterology. 1984;1:1-9.

4. Chen DS, Sung JL. Hepatitis B virus infection on Taiwan [Letter]. N Engl J Med. 1977;297:668-9. [PMID: 757978]

5. Chang MH. Natural history of hepatitis B virus infection in children. J Gastroenterol Hepatol. 2000;15(Suppl):E16-9. [PMID: 10921376]

6. Hsu HY, Chang MH, Chen DS, Lee CY, Sung JL. Baseline seroepidemiology of hepatitis B virus infection in children in Taipei, 1984: a study just before mass hepatitis B vaccination program in Taiwan. J Med Virol. 1986;18:301-7. [PMID: 2940332]

7. Stevens CE, Beasley RP, Tsui J, Lee WC. Vertical transmission of hepatitis B antigen in Taiwan. N Engl J Med. 1975;292:771-4. [PMID: 1113797]

8. Chen DS, Hsu NH, Sung JL, Hsu TC, Hsu ST, Kuo YT, et al. A mass vaccination program in Taiwan against hepatitis $B$ virus infection in infants of hepatitis B surface antigen-carrier mothers. JAMA. 1987;257:2597-603. [PMID: 3573257]

9. Hsu HM, Lu CF, Lee SC, Lin SR, Chen DS. Seroepidemiologic survey for hepatitis B virus infection in Taiwan: the effect of hepatitis B mass immunization. J Infect Dis. 1999;179:367-70. [PMID: 9878020]

10. Chang MH, Chen CJ, Lai MS, Hsu HM, Wu TC, Kong MS, et al. Universal hepatitis B vaccination in Taiwan and the incidence of hepatocellular carcinoma in children. Taiwan Childhood Hepatoma Study Group. N Engl J Med. 1997;336:1855-9. [PMID: 9197213]

11. Tsen YJ, Chang MH, Hsu HY, Lee CY, Sung JL, Chen DS. Seroprevalence of hepatitis B virus infection in children in Taipei, 1989: five years after a mass hepatitis B vaccination program. J Med Virol. 1991;34:96-9. [PMID: 1832440] 12. Chen HL, Chang MH, Ni YH, Hsu HY, Lee PI, Lee CY, et al. Seroepidemiology of hepatitis $\mathrm{B}$ virus infection in children: ten years of mass vaccination in Taiwan. JAMA. 1996;276:906-8. [PMID: 8782640]

13. Department of Budget, Accounting, and Statistics, Taipei City government, Taiwan. Available at www.dbas.taipei.gov.tw/stat/express/index.htm. Accessed on 12 September 2001.

14. Lin HH, Hsu HY, Lee TY, Hsieh RP, Chen PJ, Chen DS. Age-specific prevalence of hepatitis B surface and e antigenemia in pregnant women in Taiwan. Asia Oceania J Obstet Gynaecol. 1994;20:141-5. [PMID: 8092958]

15. Tang JR, Hsu HY, Lin HH, Ni YH, Chang MH. Hepatitis B surface antigenemia at birth: a long-term follow-up study. J Pediatr. 1998;133:374-7. [PMID: 9738719]

16. Carman WF, Zanetti AR, Karayiannis P, Waters J, Manzillo G, Tanzi E, et al. Vaccine-induced escape mutant of hepatitis B virus. Lancet. 1990;336:325-9. [PMID: 1697396]

17. Hsu HY, Chang MH, Liaw SH, Ni YH, Chen HL. Changes of hepatitis B surface antigen variants in carrier children before and after universal vaccination in Taiwan. Hepatology. 1999;30:1312-7. [PMID: 10534356]

18. Lee PI, Lee CY, Huang LM, Chang MH. Long-term efficacy of recombinant hepatitis $B$ vaccine and risk of natural infection in infants born to mothers with hepatitis B e antigen. J Pediatr. 1995;126:716-21. [PMID: 7751994]

(C) 2001 American College of Physicians-American Society of Internal Medicine 